\title{
Forest Change and Its Effect on Biomass in Yok Don National Park in Central Highlands of Vietnam Using Ground Data and Geospatial Techniques
}

\author{
Nguyen Viet Luong ${ }^{1}$, Ryutaro Tateishi ${ }^{2}$, Nguyen Thanh Hoan ${ }^{3}$, To Trong $\mathbf{T u}^{1}$ \\ ${ }^{1}$ Space Technology Institute, Vietnam Academy of Science and Technology, Hanoi, Vietnam \\ ${ }^{2}$ Center for Environmental Remote Sensing, Chiba University, Chiba, Japan \\ ${ }^{3}$ Institute of Geography, Vietnam Academy of Science and Technology, Hanoi, Vietnam \\ Email: nvluong@sti.vast.vn
}

Received 15 March 2015; accepted 1 June 2015; published 5 June 2015

Copyright (C) 2015 by authors and Scientific Research Publishing Inc.

This work is licensed under the Creative Commons Attribution International License (CC BY). http://creativecommons.org/licenses/by/4.0/

c) (i) Open Access

\section{Abstract}

This paper assesses the changes in forest cover in Yok Don National Park of Vietnam between 2004 and 2010, and the implications of such changes on the biomass stocks of this national park. Remote sensing and GIS tools along with the ground truth data collected from the field were employed for classifying the forest types of the study area from SPOT HRV satellite imagery for years 2004 and 2010. The total area considered in this study is 115.5 thousand ha. Five different categories of forests were identified. The results demonstrated that between 2004 and 2010, the Evergreen broad leaved rich quality forest decreased by 11.2 thousand ha (3.5 Mega tons of biomass) and the Dry open dipterocarps medium quality forest decreased by 15.3 thousand ha (2.5 Mega tons of biomass). In that time period, the Evergreen broad leaved medium quality forest increased by 3.2 thousand ha ( 0.8 Mega tons of biomass), the Evergreen broad leaved poor quality forest increased by 2.5 thousand ha (0.24 Mega tons of biomass), and the Dry open dipterocarps poor quality forest increased by 3.2 thousand ha (0.69 Mega tons of biomass). Total biomass of the study area decreased by 4.3 Mega tons.

\section{Keywords}

Satellite Data, SPOT HRV, Land Cover Change, Tropical Forest Biomass

\section{Introduction}

Nowadays, climate change is no longer a prediction but has become a threat and a serious challenge to human-

How to cite this paper: Luong, N.V., Tateishi, R., Hoan, N.T. and Tu, T.T. (2015) Forest Change and Its Effect on Biomass in Yok Don National Park in Central Highlands of Vietnam Using Ground Data and Geospatial Techniques. Advances in Remote Sensing, 4, 108-118. http://dx.doi.org/10.4236/ars.2015.42010 
kind globally, including Vietnam. Climate change and its relation to $\mathrm{CO}_{2}$ emissions are a matter of global concern. Forest ecosystem plays a very important role in the global carbon cycle; the $\mathrm{CO}_{2}$ from the atmosphere is taken up by vegetation and stored as plant biomass. Biomass is defined as the total amount of aboveground living organic matter in trees expressed as oven-dry tons per unit area [1] and tropical forests hold large stores of carbon [2]. According to FAO (2010), the world's total forest area is just over 4 billion ha and covers 31 percent total land area and estimated store $289 \mathrm{Gt}$ of carbon in their biomass alone. However, carbon stocks in forest biomass decreased by an estimated 0.5 Gt annually during the period 2005-2010, mainly because of a reduction in the global forest area [3]. In Southeast Asia region, total forest cover is estimated at $268 \mathrm{M}$ ha in 1990, dropping to $236 \mathrm{M}$ ha in 2010 , with annual change rates of $1.75 \mathrm{M}$ ha $(\sim 0.67 \%)$ and $1.45 \mathrm{M}$ ha $(\sim 0.59 \%)$ for the periods 1990-2000 and 2000-2010, respectively [4].

The quantifying of biomass and carbon sequestration in tropical forests is particularly relevant within the United Nations Framework Convention on Climate Change (UNFCC). Kyoto Protocol recognized the role of forests in carbon stock and pointed out forest as potential carbon storage in Articles 3.3 and 3.4 [5] of The Reducing Emission from Deforestation and Forest Degradation (REDD) program. In the effort towards mitigating global climate change, the initiative of reducing emission from deforestation and forest degradation (REDD) was proposed in COP 13 in Bali, Indonesia in 2007 and this initiative was formally adopted as a measure contributing to climate change mitigation, because, emission of GHGs from land use change, particularly the conversion of forestland to non-forestland, and unsustainable forest management, were claimed to contribute to as much as 20 percent of global GHG emissions [6]. The UN-REDD programs are being carried out in nine countries including Vietnam. Under the REDD mechanism, countries will need to measure and monitor the emissions of $\mathrm{CO}_{2}$ resulting from deforestation and degradation within their borders. In other words, the countries participating in this program should have a system: "Measurement, Evaluation and Report" system (MRV) [6]. However, the majority of countries do not have time series data on growing stock, so the weaknesses in growing stock trend estimates is also directly translated into biomass [3].

The remote sensing science and application communities have developed increasingly reliable and consistent [7]. A more comprehensive and reliable approach for estimating biomass change is to combine new field studies with analysis of high resolution remote sensing imagery [1]. The strengths of remote sensing come from its ability to provide spatially explicit information and repeated coverage including the possibility of covering large areas as well as remote areas that are difficult to access otherwise [8]. Remote sensing technologies can provide objective, practical and cost-effective solutions for developing and maintaining REDD+ monitoring systems [9]. Vietnam conducts a national forest survey every five years using optical satellite imagery from SPOT satellites and ground survey data. Hence, forest cover estimation has been periodically assessed. However, estimation of change in biomass due to changes in forest types has not been of research interest despite its importance in the face of climate change and applicability for REDD implementation. Therefore, this research aimed to fulfill an important research gap by estimating quantity and direction of change in forest types and its effects on biomass in tropical forests. The approach used in this study effectively applies ground truth data and geospatial techniques for estimating changes in forests and biomass and has potential to be adopted elsewhere.

\section{Study Area}

The Yok Don National Park is located Dak Lak province in the Central Highlands, total area is 115.5 thousand ha. It is one of the largest nature conservation areas of Vietnam. The study area lies between; $12^{\circ} 45^{\prime} \mathrm{N}-13^{\circ} 10^{\prime} \mathrm{N}$ Latitude and $107^{\circ} 29^{\prime} \mathrm{E}-107^{\circ} 48^{\prime} \mathrm{E}$ Longitude (Figure 1). Most of the park lies at $200 \mathrm{~m}$ elevation and the terrain is relatively flat. There are, however, several ranges of low hills within the national park, the highest point of which is the eponymous Mount Yok Don at $482 \mathrm{~m}$ in the south-eastern range [10] [11].

Flora at Yok Don National Park is dominated by species of Dipterocarpaceae family, including Dipterocarpus tuberculatus, Dipterocarpus obtusifolius, Shorea obtuse, etc. However, the Anacardiaceae, Combretaceae, Fabaceae and Myrtaceae families are also well represented. The canopy of this forest type is open, and most trees have thick, fire-resistant bark [12] and tree canopies of predominant deciduous phenology during dry season [13]. Evergreen forests are distributed in higher elevations on the south-east slopes in the national park. These forest types are denser, and are dominated by the species from families as Fagaceae, Euphorbiaceae, Sapindaceae, Ebenaceae and Meliaceae [12]. According to Thin (2007), 854 vascular plant species belongs to 478 genera and 129 families, of which 28 are listed in the Red Data Book of Vietnam, have been recorded in the national park [14]. 


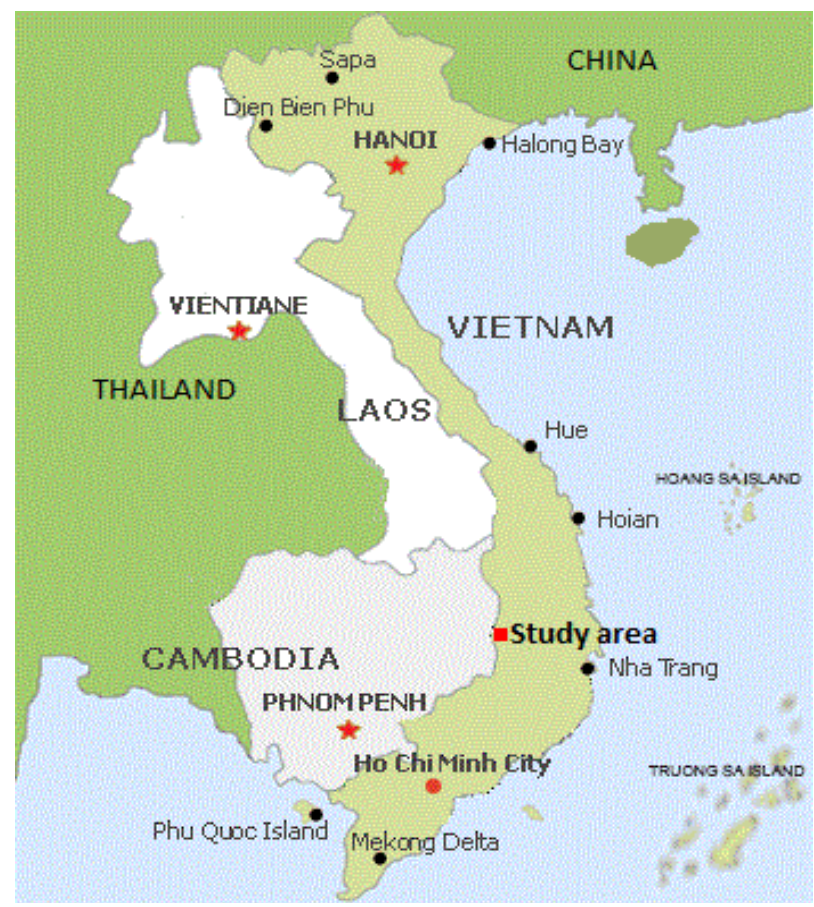

Figure 1. Local map of the study area.

\section{Data and Methodology}

\subsection{Satellite Data}

The use of satellite images for the change detection procedures should involve data acquired in the same sensor and also having same spatial resolution, spectral bands and viewing geometry. Especially, seasonal element in the deciduous forest region, because leaf shedding over the course of the dry season [15]. This study has used the SystèmeProbatoire de l'Observation de la Terre (SPOT) satellite data with $10 \mathrm{~m}$ spatial resolution SPOT-5 acquired in May 2004 and May 2010. The technical details of the satellite data used in the present study are given in Table 1 and Figure 2.

\subsection{Satellite Image Processing}

The method of satellite images processing in this study includes: Geometric correction, Image to map rectification by terrain map sheet on scale 1:50,000. Change detection analysis was used the Post classification comparison method (based on supervised classification) was adopted for change analysis.

\subsection{Field Work}

Fieldwork helps to collect and check most of the ground information required for the mapping purpose (Figure 2). Ground survey data are usually classified to provide estimates of the land cover and its corresponding area, and usually require ground survey data to provide an estimate of the classification accuracy [8]. The reconnaissance field survey was undertaken to get acquainted with the general patterns of vegetation types in the study area. Major vegetation types and few prime localities of characteristic types were recorded. The variation and tonal patterns were observed on existing images. Traverses along all main roads, trail roads inside forest, dry rivers were made for collecting ground truth between maps/images and on the ground. Various features were identified for establishing correlation with image element on FCC image (2010) and terrain map sheet on 1:50,000 scales. Correct GPS locations were obtained for various land cover types and land use categories. Ground truth data collection was conducted twice within the survey duration. Ground truth data were collected during the first survey and again independent samples were collected during second survey for checking the accuracy of the data. 
Table 1. Details of satellite data used in the study.

\begin{tabular}{ccccccc}
\hline No. & Satellite & Sensor & Date of pass & Total bands & Spectral bands used & Spatial resolution (m) \\
\hline 1 & Spot 5 & HRV & May 25, 2004 & 3 & $1,2,3$ & 10 \\
2 & Spot 5 & HRV & May 15, 2010 & 3 & $1,2,3$ & 10 \\
\hline
\end{tabular}

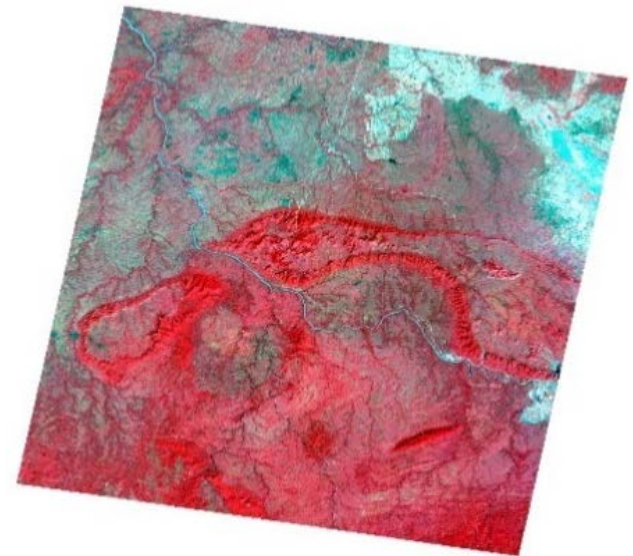

(a)

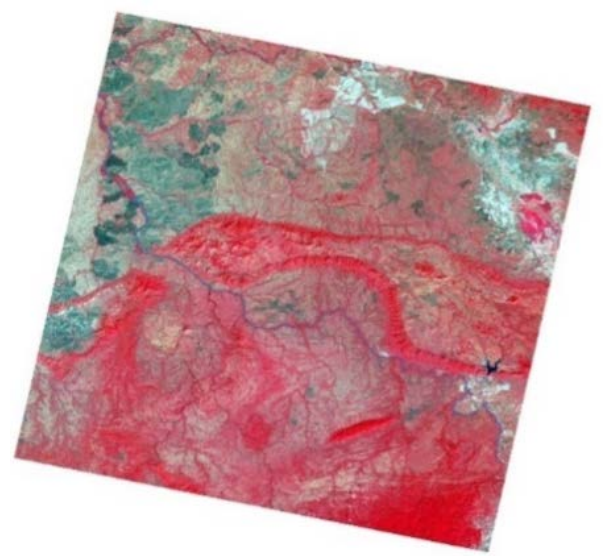

(b)

Figure 2. SPOT HRV False Colour Composite (a) 2004, (b) 2010.

Sample plot establishment and measurement of parameter of structural forest cover based on of guidance of relevant previous research [1] [2] [16]-[19]. The size and shape of the sample plots is a trade-off between accuracy, precision, time, and cost of measurement. The establishment of sample plots needs to meet the following criteria: i) representativeness of the forest types being studied; ii) representativeness for topographic conditions; iii) covering a number of different trees sizes [19]. The most appropriate size and shape may also be dependent on the vegetation type and the type of satellite data used. In this study, a typical sample plot of $500 \mathrm{~m}^{2}(25 \mathrm{~m} \times$ $20 \mathrm{~m}$ ) was used for Dry open dipterocarps and $1000 \mathrm{~m}^{2}$ was used for Evergreen broad-leaved forest. At each sample plot various information on the individual woody trees such as the diameter at breast height $\left(\mathrm{D}_{13}\right)$ and height of trees and name of tree species (local and scientific names) were recorded.

\subsection{Forest Cover Classification}

Satellite imagery from SPOT 2004 and SPOT 2010 were employed for image classification. These data came from the same month (May). Therefore the advantage of these data is that they may yield higher accuracy in detecting change between two time periods. This classification schemes allows forest managers to easily identify different land cover types and use for management purpose. This study applied classification system of Trung (1973) [20], Trung(1978) [21] and the results of the forest and vegetation cover classes mapped of Stibiget al (2004) [16] and was adopted classification criteria of the UNESSCO (1973) [22] for the classification into 2 main classes of forest coverare Evergreen broad leaved forest, Dry open dipterocarps forest and then use the Circular No. 34/TT-BNN [23] issued by Ministry of Agriculture and Rural Development (MARD) of Vietnamese government (2009) for the detailed classification into 6 classes of forest cover with the rich forest comprised a forest with a standing wood volume over $200 \mathrm{~m}^{3} / \mathrm{ha}$, the medium forest with $101-200 \mathrm{~m}^{3} / \mathrm{ha}$ and the poor forest included the forest with $10-100 \mathrm{~m}^{3} / \mathrm{ha}$. Originally the forest in this ecosystem zone was classified in to 6 classes. However, as the results of this investigation, the forest vegetation of the study area has the 5 classes only as 1) Evergreen broad leaved rich forest (EB rich forest), 2) Evergreen broad leaved medium forest (EB medium forest), 3) Evergreen broad leaved poor forest (EB poor forest), 4) Dry open dipterocarps medium forest (DD medium forest) and 5) Dry open dipterocarps poor forest (DD poor forest), because Dry open dipterocarps rich forest does not exist in the study area.

Additionally, other land cover categories may be identified [22] as 6) Another land cover (mainly composed of woody tree from 0.5 to $5 \mathrm{~m}$ tall); scrubland, (most of the individual shrubs not touching each other, often with a grass stratum); Thicket (individual shrubs interlocked and barreland) and 7) Water body. 


\begin{tabular}{cc}
\hline $\begin{array}{c}\text { Stibiget al. (2004) [13], Trung (1973, 1978) [20] [21] } \\
\text { and UNESSCO (1973) [22] }\end{array}$ & $\begin{array}{c}\text { Circular No. 34/TT-BNN issued } \\
\text { by MARD (2009) [23] }\end{array}$ \\
\hline & 1. EB rich forest \\
Evergreen broad-leaved forest (EB forest) & 2. EB medium forest \\
& 3. EB poor forest \\
Dry open Dipterocarps (DD forest) & 4. DD medium forest \\
Another land cover & 5. DD poor forest \\
Water body & 6. Another land cover \\
\end{tabular}

\subsection{Method for Determining Forest Biomass}

Above-ground biomass and changes can be derived in two ways [2] [24], namely, i) directly by measuring sample tree attributes in the field, such as diameters and heights, and applying, species-specific allometric equations. (ii) indirectly by transforming available volume data from forest inventories.This study applied first way and the allometric equation developed for the estimate of above ground biomass of Evergreen broad-leaved and Dry open dipterocarps forest. These allometric equations for estimating biomass (correlation model) were developed by the UN-REDD program in 2012 [25] for the Highlands of Vietnam. The optimal equations for biomass estimation at tree level:

For Evergreen broad leaved forests, the optimal model for biomass estimation is:

$$
\text { AGB }=0.0530 *\left(D^{2} * \mathrm{H}^{0.7}\right)^{1.0072}
$$

For Dry open dipterocarps, the optimal model for biomass estimation is:

$$
\text { AGB }=0.0154 *\left(D^{2 *} \mathrm{H}^{0.7}\right)^{1.1682}
$$

where:

AGB-Above ground tree biomass;

D-Diameter at breast height of tree;

$\mathrm{H}-$ Height of tree stand.

\section{Results}

\subsection{The Parameter of Structure and Biomass of Forest Cover}

This study focuses on the current state of large biomass vegetation. The results from the sample plots were used to calculate the parameters of structure and biomass of forest cover at Yok Don National Park for the current state of five forest cover types include Evergreen broad-leaved rich forest (EB rich forest); Evergreen broadleaved medium forest (EB medium forest); Evergreen broad-leaved poor forest (EB poor forest); Dry open dipterocarps medium forest (DD medium forest) and Dry open dipterocarps poor forest (DD poor forest). The parameters of structure of forest cover include the diameter of breast height at $1.3 \mathrm{~m}$ position $\left(\mathrm{D}_{1.3}>5 \mathrm{~cm}\right)$, height at from bottom to top of wood tree $\left(\mathrm{H}_{\mathrm{vn}}\right)$, height of wood tree under branch $\left(\mathrm{H}_{\mathrm{dc}}\right)$, density of wood tree/ha $(\mathrm{N} / \mathrm{ha})$. The results are shown in Table 2 and Figure 3.

\subsection{Land Cover Map of 2004}

Land cover map based on supervised classification of SPOT 2004 is shown in Figure 4 and area analysis of land

Table 2. The parameters of the structure and biomass of forest cover.

\begin{tabular}{ccccccc}
\hline No. & Class & $\mathbf{D}_{\mathbf{1 . 3}} \mathbf{( c m )}$ & $\mathbf{H}_{\mathbf{v n}}(\mathbf{m})$ & $\mathbf{H}_{\mathbf{d c}}(\mathbf{m})$ & $\mathbf{N} / \mathbf{h a}($ tree) & Biomass (tons/ha) \\
\hline 1 & EB rich forest & 30.69 & 17.3 & 9.55 & 503 & 318.38 \\
2 & EB medium forest & 26.6 & 12.07 & 8.61 & 545 & 249.98 \\
3 & EB poor forest & 18.44 & 10.71 & 4.23 & 409 & 101.06 \\
4 & DD medium forest & 21.98 & 13.09 & 8.08 & 615 & 163.87 \\
5 & DD poor forest & 15.11 & 8.42 & 4.45 & 831 & 54.79 \\
\hline
\end{tabular}




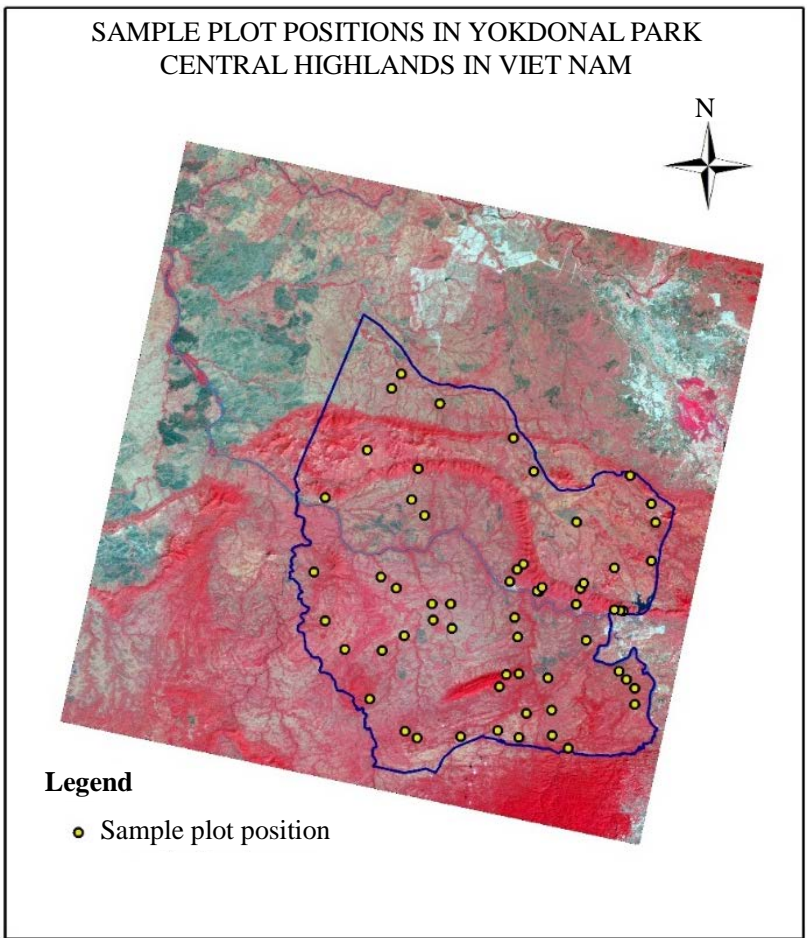

Figure 3. Sample plot positions in Yok Don National Park.

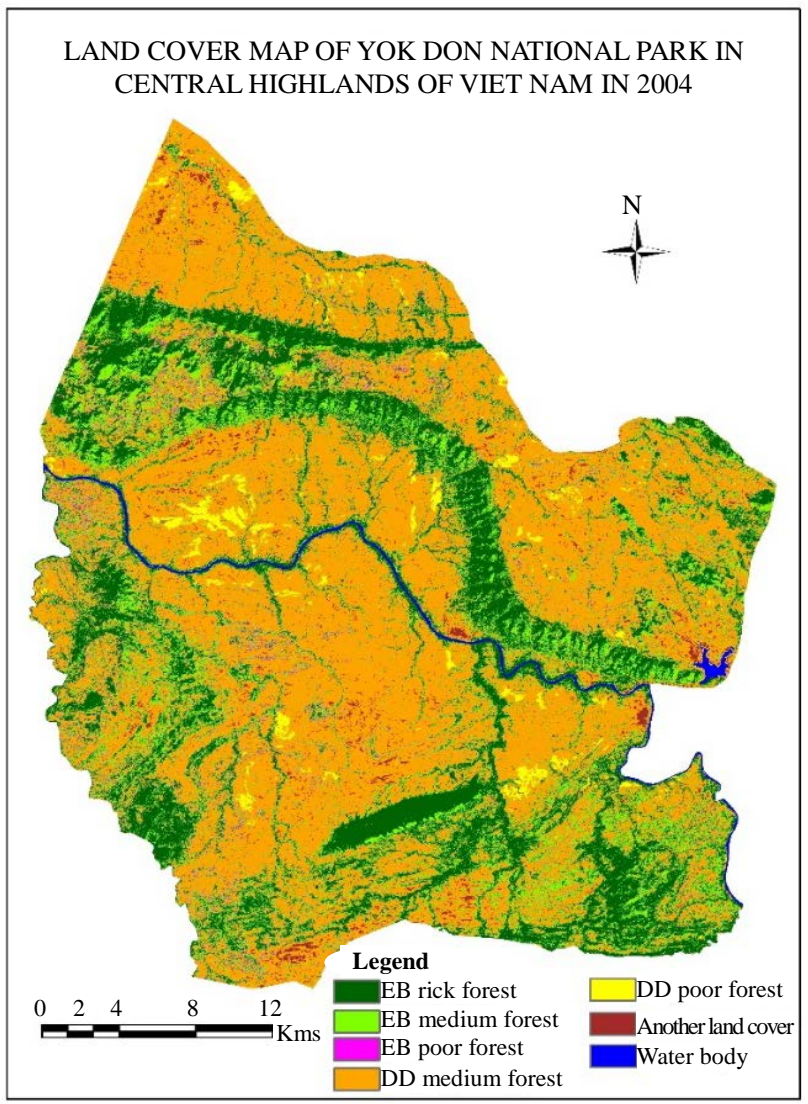

Figure 4. Land cover map in 2004. 
cover is shown in Histogram 1. The EB rich forest 23.7 thousand ha (20.53\%), EB medium forest area is 21.2 thousand ha (18.35\%), EB poor forest area is 9.3 thousand ha (8.03\%), DD medium forest area is 53.2 thousand ha (46.05\%), DD poor forest area is 7.2 thousand ha (6.21\%), Another land cover area is 297 ha $(0.26 \%)$ and Water body area is 676 thousand ha $(0.59 \%)$.

The results of the assessment accuracy of the forest cover map of year 2004 are: $84.3 \%$ as overall accuracy, $86.7 \%$ as producer accuracy and $84.3 \%$ as user accuracy.

\subsection{Land Cover Area of 2010}

The land cover map based on supervised classification for 2010 is shown in Figure 5 and the area statistics for land cover of 2010 is shown in Histogram 1. The EB rich forest area is 12.5 thousand ha (10.85\%), EB medium forest area is 24.4 thousand ha (21.12\%), EB poor forest area is 11.7 thousand ha (10.16\%), DD medium forest

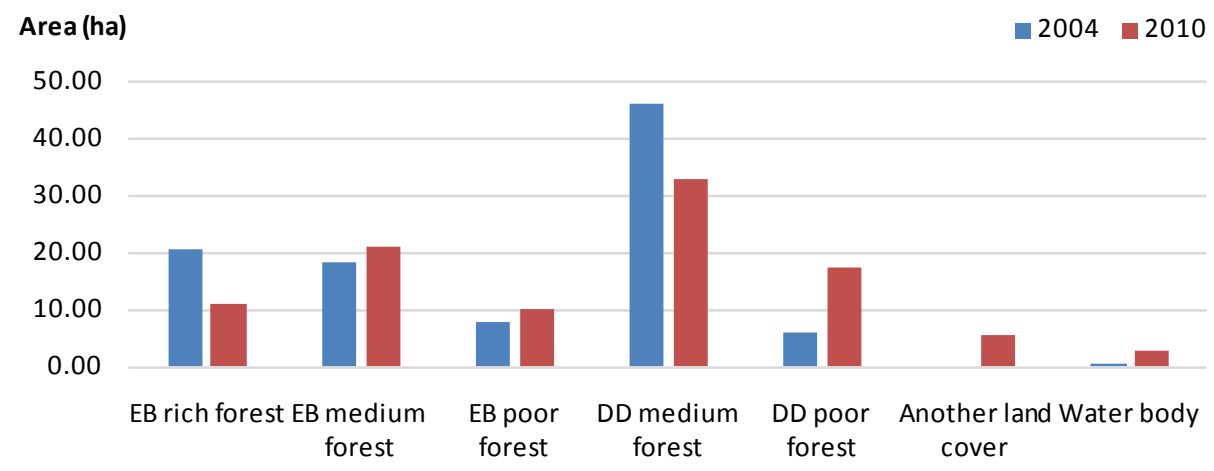

Histogram 1. Comparing the land cover area in 2004 and 2010.

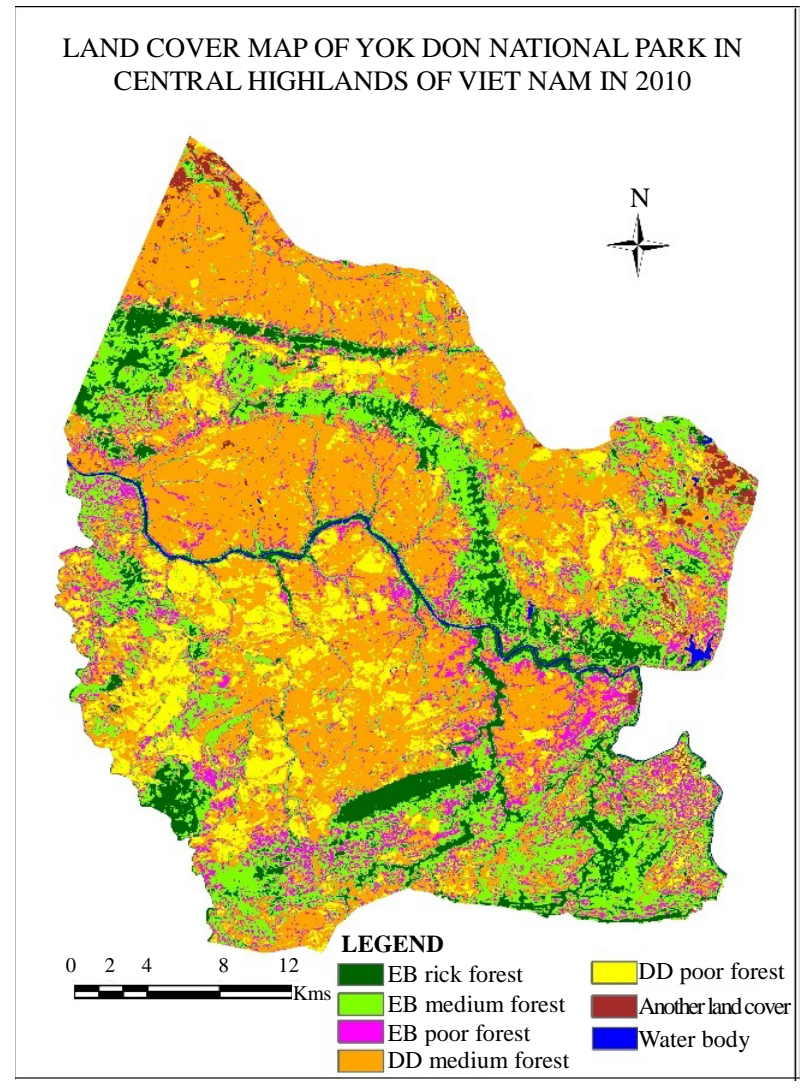

Figure 5. Land cover map in 2010. 
area is 37.9 thousand ha (32.77\%), DD poor forest area is 19.9 thousand ha (17.19\%), Another land cover area is 6.2 thousand ha (5.9\%) and Water body area is 2.9 thousand ha (2.55\%).

The results of the assessment accuracy of the forest cover map of year 2010 are: $86.6 \%$ as overall accuracy, $87.3 \%$ as producer accuracy and $84.7 \%$ as user accuracy

\subsection{Land Cover Change Map}

The results of geospatial change maps from 2004 to 2010 based on post classification comparison method are shown in Histogram 1, Table 3, Table 4 and Figure 6. The analysis indicates that the EB medium quality forest increased by 3.2 thousand ha, EB poor quality forest increased by 2.5 ha and DD poor quality forest increased by 12.7 thousand ha. While the EB rich quality forest decreased by 11.2 thousand ha and DD medium quality forest decreased by 15.3 thousand ha. The analysis also indicate that another land cover increased by 5.9 thousand ha and water body increased by 2.3 thousand ha.

\subsection{Estimates of Biomass and Biomass Change}

The results of the estimation of biomass based on the data from the parameters of the structure and biomass of land cover are depicted in the Table 2 and land cover and land cover change area are presented in the Table 3 and the allometric Equation (1) and Equation (2) above for the years are found in (Table 5) depicting the change in biomass between 2004 and 2010.

\section{Conclusions}

This study demonstrates the applicability of temporal data sets (2004 and 2010) from SPOT HRV satellite and the ground data for mapping forest types and analyzing the forest change. This method has been effectively employed for mapping of land cover in Yok Don National Park, Highlands of Vietnam with overall classification accuracy of $84.30 \%$ to $86.62 \%$. The analysis indicated that during period 2004 and 2010, the EB rich quality forest decreased by 11.2 thousand ha, equivalent to 3.5 Mega tons of biomass; the DD medium quality forest

\begin{tabular}{cccccccccc}
\multicolumn{2}{l}{ Table 3. Area change matrix for the period 2004 to 2010 (units: ha). } \\
$\begin{array}{ccccccccc}\text { EB rich } \\
\text { 2004/2010 }\end{array}$ & $\begin{array}{c}\text { EB medium } \\
\text { forest }\end{array}$ & $\begin{array}{c}\text { EB poor } \\
\text { forest }\end{array}$ & $\begin{array}{c}\text { DD medium } \\
\text { forest }\end{array}$ & $\begin{array}{c}\text { DD poor } \\
\text { forest }\end{array}$ & $\begin{array}{c}\text { Another land } \\
\text { cover }\end{array}$ & Water body & Total \\
\hline EB rich forest & 10354.85 & 9586.79 & 3034.23 & 50.74 & 50.55 & 414.77 & 226.62 & 23718.55 \\
EB medium forest & 1868.67 & 12797.10 & 5489.01 & 73.85 & 16.54 & 499.38 & 453.83 & 21198.38 \\
EB poor forest & 282.08 & 1982.24 & 3164.41 & 63.76 & 55.10 & 2584.91 & 1140.33 & 9272.83 \\
DD medium forest & 14.23 & 13.76 & 19.74 & 35999.50 & 14471.30 & 2258.05 & 428.88 & 53205.46 \\
DD poor forest & 7.46 & 10.26 & 14.69 & 1637.14 & 5212.82 & 231.26 & 62.59 & 7176.22 \\
Another land cover & 1.66 & 2.80 & 6.93 & 30.01 & 50.31 & 197.83 & 7.96 & 297.50 \\
Water body & 8.84 & 9.58 & 7.18 & 8.39 & 9.41 & 1.92 & 631.22 & 676.54 \\
Total & 12537.79 & 24402.53 & 11736.19 & 37863.39 & 19866.03 & 6188.12 & 2951.43 & 115545.48 \\
\hline
\end{tabular}

Table 4. Area change distribution during 2004 and 2010.

\begin{tabular}{cccc} 
No. & Class & Area (ha) & Percent (\%) \\
\hline 1 & Non change & 68357.73 & 59.16 \\
2 & Positive change & 5987.3 & 3.18 \\
\hline
\end{tabular}




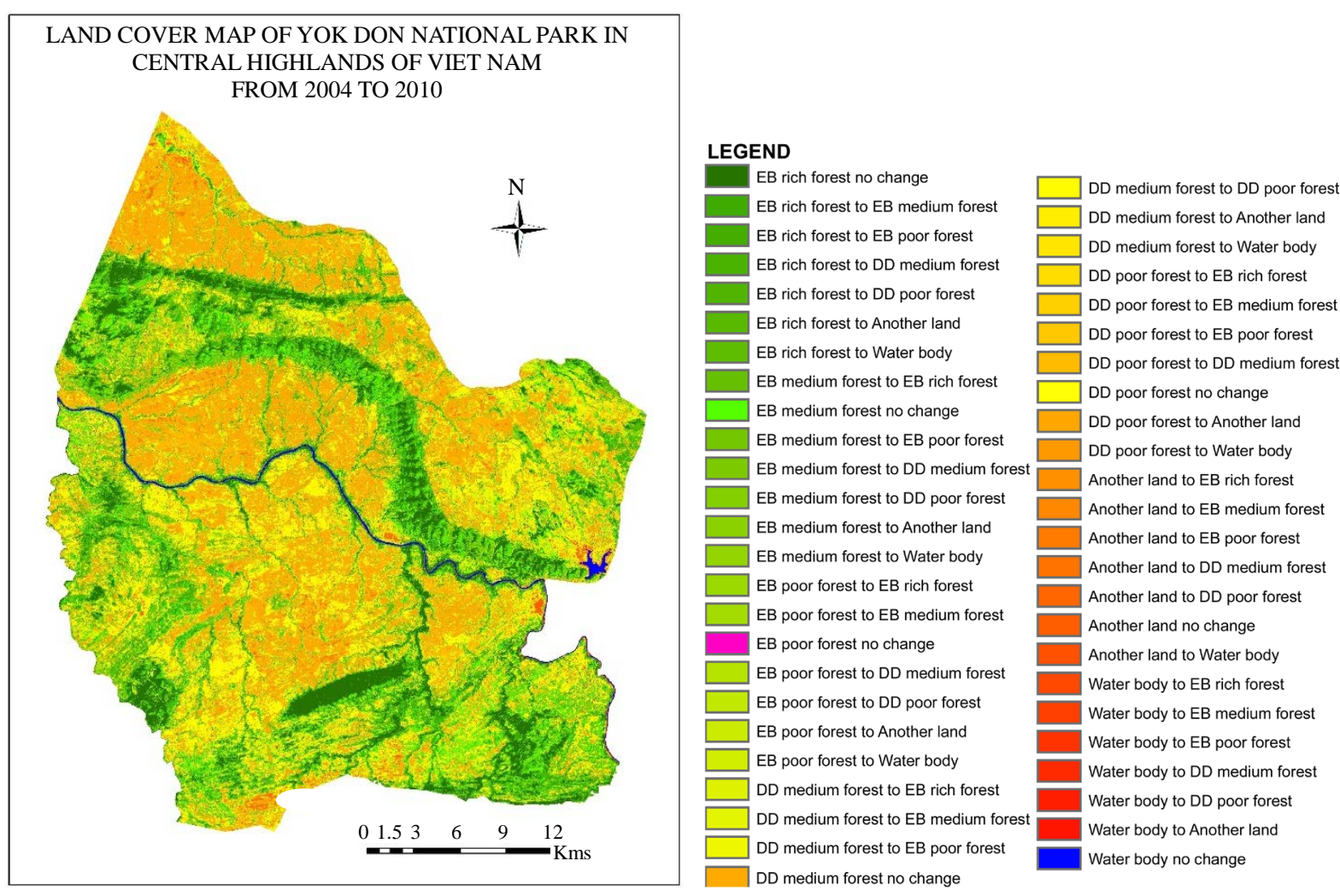

Figure 6. Land cover change map from 2004 to 2010.

Table 5. Biomass and biomass change in during 2004 and 2010.

\begin{tabular}{ccccc}
\hline & & \multicolumn{2}{c}{ Biomass (tons) } & Biomass change (tons) \\
\cline { 3 - 4 } No. & Class/Year & 2004 & 2010 & -3559730.37 \\
\hline 1 & EB rich forest & 7551511.95 & 3991781.58 & 800973.42 \\
3 & EB medium forest & 5299171.03 & 6100144.45 & 248947.16 \\
4 & EB poor forest & 937112.20 & 1186059.36 & -2514105.01 \\
5 & DD medium forest & 8718778.73 & 6204673.72 & 695274.69 \\
\hline
\end{tabular}

decreased 15.3 thousand ha, equivalent to 2.5 Mega tons of biomass. In that time period, the EB medium quality forest increased by 3.2 thousand ha, equivalent to 0.8 Mega tons of biomass; the EB poor quality forest increased by 2.4 thousand ha, equivalent to 0.24 Mega tons of biomass; the DD poor quality forest increased by 12.68 thousand ha, equivalent to 0.69 Mega tons of biomass. The analysis of area change matrix indicated that the non-change area was 68.3 thousand ha (59.16\%), the positive change area was 5.9 thousand ha (5.18\%) and that the negative change area was 41.2 thousand ha (35.66\%), where the much of these EB rich forest and DD medium forest got converted to EB medium forest and DD poor forest respectively. The total biomass of the study area decreased by 4.3 Mega tons. The analysis also indicated that another land cover increased by 5.9 thousand ha and that water body increased by 2.3 thousand ha. Based on the findings of this study, the following recommendations arise:

- Using satellite images with high resolution for preparing land cover map and land cover change map will aid in monitoring forest conditions. Combining this information with the field data can also be useful for esti- 
mating biomass stock and sequestered carbon aiding in the evaluation of the existing forest resources in terms of its ability to reduce carbon emissions. We recommend forest change analyses to be performed on a yearly base to monitor the forest's condition and the ecosystem services it may provide;

- Should be build a permanent sample plot network in the forested areas so that a consistent sample can be obtained for monitoring forest status annually;

- Should be development the use of radar data for structure of forest, as well as the directly calculation and monitoring of the forest biomass for in the study area.

\section{Acknowledgements}

The authors are highly grateful to the project No. VAST01.03/15-16 from Vietnam Academy of Science and Technology (VAST) and Japan Society for the Promotion of Science (JSPS) have supported, encouraged and provided funding for this study.

\section{References}

[1] Brown, S. (1997) Estimating Biomass and Biomass Change of Tropical Forests: A Primer. FAO Forestry Paper, 134, ISBN 92-5-103955-0.

[2] Chave, J., Andalo, C., Brown, S., Cairns, M.A., et al. (2005) Tree Allometry and Improved Estimation of Carbon Stocks and Balance in Tropical Forests. Oecologia, 145, 87-99. http://dx.doi.org/10.1007/s00442-005-0100-x

[3] FAO (2010) Global Forest Resources Assessment 2010-Main Report. FAO Forestry Paper 163, Rome, 378 p.

[4] Stibig, H.J., Achard, F., Carboni, S., Rasi, R. and Miettinen, J. (2014) Change in Tropical Forest Cover of Southeast Asia from 1990 to 2010. Biogeosciences, 11, 247-258.

[5] United Nations (1998) Kyoto Protocol to the United Nations Framework Convention on Climate Change.

[6] UN-REDD Vietnam Programme (2012) Guidelines on Destructive Measurement for Forest Biomass Estimation for Technical Staff Use, 35 p. (Version for Discussion)

[7] Olofsson, P., Foody, G.M., Herold, M., Stehman, S.V., Woodcock, C.E. and Wulder, M.A. (2014) Good Practices for Estimating Area and Assessing Accuracy of Land Change. Remote Sensing of Environment, 148, 42-57. http://dx.doi.org/10.1016/j.rse.2014.02.015

[8] IPCC (2003) Good Practice Guidance for Land Use, Land-Use Change and Forestry. IPCC National Greenhouse Gas Inventories Programme Technical Support Unit, Printed in Japan, ISBN 4-88788-003-0.

[9] De Sy, V., et al. (2012) Synergies of Multiple Remote Sensing Data Sources for REDD+ Monitoring. Current Opinion in Environmental Sustainability, 4, 696-706. http://dx.doi.org/10.1016/j.cosust.2012.09.013

[10] Canh, N.X., et al. (2009) Report on Conservation Planning and Sustainable Development of Yok Don National Park in 2010-2020. Ministry of Agriculture and Rural Development (MARD), 140 p.

[11] Luong, N.V. (2011) Essay to Use Remote Sensing Images to Estimate Biomass as a Basis for Calculating the Amount of $\mathrm{CO}_{2}$ Sequestration by Vegetation Cover in Yokdon National Park, Highlands of Viet Nam. Proceedings of the Scientific Conference on Research, Development and Application of Space Technology, Hanoi, 10-14 October 2011, 9 p.

[12] Anonymous (1998) The Investment Project to Expand the Yok Don National Park. Forest Inventory and Planning Institute, Hanoi.

[13] Stibig, H.J., Achard, F. and Fritz, S. (2004) A New Forest Cover Map of Continental Southeast Asia Derived from SPOT-VEGETATION Satellite Imagery. Applied Vegetation Science, 7, 153-162. http://dx.doi.org/10.1111/j.1654-109X.2004.tb00606.X

[14] Thin, N.N., Duc, N.A., Tai. V.A., Thanh, N.T.K. and Dung, N.T. (2008) Update Information of Flora and Plant's Resources of Yokdon National Park, Daclak Province. http://www.botanyvn.com/cnt.asp?param=news\&newsid=46\&lg=en

[15] Langner, A., Hirata, Y., Saito, H., Sokh, H., Leng, C., Pak, C. and Raši, R. (2014) Spectral Normalization of SPOT 4 Data to Adjust for Changing Leaf Phenology within Seasonal Forests in Cambodia. Remote Sensing of Environment, 143, 122-130. http://dx.doi.org/10.1016/j.rse.2013.12.012

[16] Bhishma, P., Shiva, S.P., Ajay, P., Eak, B.R., Sanjeeb, B., Tibendra, R.B., Shambhu, C., Rijan, T., et al. (2010) Forest Carbon Stock Measurement-Guidelines for Measuring Carbon Stocks in Community-Managed Forest. Asia Network for Sustainable Agriculture and Bioresource (ANSAB), Nepal, 679 p.

[17] Chaiyo, U., Garivait, S. and Wanthongchai, K. (2011) Carbon Storage in Above-Ground Biomass of Tropical Deciduous Forest in Ratchaburi Province, Thailand. World Academy of Science, Engineering and Technology, 58, 636-641. 
[18] Huy, B. (2008) Methodology for Research on $\mathrm{CO}_{2}$ Sequestration in Natural Forests to Join the Program of Reducing Emission from Deforestation and Degradation-REDD. Journal of Agriculture and Rural Development, 10, 1-10.

[19] UN-REDD Vietnam Programme (2011) Technical Manual for Participatory Carbon Monitoring.

[20] Trung, T.V. (1978) The Vegetation Cover in Vietnam. Chapter IV, V, 2nd Edition, Science and Technics Publishing House, Hanoi, 276 p.

[21] Trung, T.V. (1998) The Tropical Forest Ecosystem in Vietnam. Chapter IV, Science and Technics Publishing House, Hanoi, 291 p.

[22] UNESCO (1973) International Classification and Mapping of Vegetation. United Nations Educational, Scientific and Cultural Organization, Paris, 102 p.

[23] Regulation on Criteria for Identifying and Classifying Forest (In English) (2009) No. Circular 34/TT-BNN Issued by Ministry of Agriculture and Rural Development (MARD) of Vietnamese Government. Quyđịnhtiêuchíxácđịnhvàphânloạirừng (In Vietnamese), Tran.

[24] IPCC (2006) Chapter 4: Forest Land. In: Guidelines for National Greenhouse Gas Inventories. Volume 4: Agriculture, Forestry and Other Land Use, IPCC.

[25] UN-REDD Vietnam Programme (2012) Tree Allometric Equation Development for Estimation of Forest AboveGround Biomass in Viet Nam. Part A-Introduction and Background of the Study Viet Nam. 